Journal of Development and Communication Studies

Vol. 5. No. 1, July 2016 - June 2017 ISSN (Online \& Print): 2305-7432.

http://www.devcomsjournalmw.org.

\title{
Mobile telephony and copresence in Marakwet, Kenya
}

Leah Jerop Komen, Senior Lecturer\& Thesis Coordinator, School of Communication, Languages \& Performing Arts, Daystar University, Kenya. lkomen@daystar.ac.ke or ledavid2002@gmail.com

\begin{abstract}
The integration of mobile phones into social life has attracted divergent views on its technosocial capacities for social transformations especially its disruption on the integrity of space and time. While celebrated as a technology that liberates users from the constraints of time and place, it is equally reviled for the defilement of place or space and face to face social encounters (copresence). This paper discusses the influence of mobile telephony on social interactions with specific focus on conversations around copresence in Marakwet. Through ethnographic interviews and observational notes, the paper argues for the need to study mobile telephony as a social assemblage. Drawing from Delanda's (2006) version of assemblage theory, the researcher finds that copresent encounters has changed the way time and place is conceptualised, with distinctions between private and public places blurred and transformation of social interaction evidenced.
\end{abstract}

Key words: mobile telephony, co-presence, assemblage, time and space, private versus public spaces

To cite this article: Komen, L.J. (2017). Mobile telephony and copresence in Marakwet, Kenya. Journal of Development and Communication Studies, 5(1): 44-55.

https://dx.doi.org/10.4314/jdcs.v5i1.3

\section{Introduction}

Communities and social networks have been transformed ever since the advent of information communication technologies specifically the mobile telephony. Przybylski and Weinstein (2012) observed that although communication technologies had enabled people to connect more easily across distances, little was known about how the presence of these devices in social settings influences face-to-face interaction (p. 1). Mediated copresence through media also brings a rather complex 
understanding of identity, In attempting to discuss the changing conceptualisation of copresence, Langmia (2016) a professor at Howard university, explains the link between the socio-cultural copresence and what he termed as teleco-presence-the idea that persons can meet online via their mobile devices online with respect to interpersonal electronic face-to-face (Skype, FaceTime, Google Hangouts etc) encounters where images are involved(p 266-267). Langmia presents identity of participants here as fluid, citing the tendency of participants to 'like and dislike', friend and unfriend', follow and unfollow on social media platforms. Here the community is defined along the territories between those who are friended but as soon as one disapproves of any behaviour or sentiments of another, he or she decides to unfriend or unfollow. This makes sense in cases where smartphones are available, what of places or situations that that is not the case? When a community physically gathered decides to conduct business and a mobile phone or phones are brought along what happens to the nature of copresence encounters?

This paper builds on Goffmanian dramaturgy (1995) of conversations and assemblage theory to understand the complexity of copresence in a rural community in Kenya. The uses of communication technologies such as mobile telephony by various members of the community in a public or social setting has given it numerous meanings and interpretations, to others it disrupts the copresence to others it enhances even a pre-requisite to a more productive face to face interaction (Baym,2010). This study posits that the influence of mobile telephony in a copresence situation is beyond the dualism of enhancing or disrupting it is an assemblage of many actors each determining and being determined as people interact with mobile technology in a social gathering in Marakwet, a rural community in western part of Kenya.

Our social systems-at work and home and elsewhere-have moved from being bound up in hierarchically arranged, relatively homogeneous, densely knit, bounded groups to being social networks. When groups are bounded up they form territories and when they disintegrate they de-territorialise, making the identity of these groups flexible. This is typical characteristic of assemblages. An assemblage is the coming together of heterogeneous parts that interact to form a whole whose identity is described along the roles and process that components play while they interact. DeLanda (2006) explains these roles as materials - which are tangible such as the mobile phone device, people etc and expressive roles, capacities of components exercised (the application such as texting, calling, spotlight etc). Processes are territorialisation and deterritorialisation. In networked societies, boundaries are more permeable, interactions are with diverse others, linkages switch between multiple networks, and hierarchies are flatter and more recursive (Wellman 1997, 1999; Castells 2000). Hence, many people communicate with others in ways that carry across group boundaries. Rather than relating to one group, people live and work in multiple sets of 
overlapped relationships, oscillating between different networks-work, leisure, social strata etc. Their work and community networks are diffuse and sparsely knit-with vague, overlapping, social, spatial boundaries and many of the people they deal with. In her ethnographic study of young migrant women from rural-to-urban China, Wallis (2013) examines mobile telephony as an assemblage. In her analysis she provides an intimate portrait of the social, cultural and economic implications of mobile communication for a group of young women engaged in semi-skilled work in China, where they work for an indefinite period of time.

Situating her work within feminist studies, technology studies and communication theory, Wallis explores the ways in which mobile telephony is being integrated into transforming the social structures and practices of contemporary China. She targets the relationship between young rural-to-urban women to show how mobile phone use empowers 'immobile mobility' (p.6). She defines 'immobile mobility' as a "sociotechno means of surpassing spatial, temporal, physical and structural boundaries" (p.6). In other words, she argues, mobile phones tie these women to certain places and jobs while also helping them to broaden their horizons and pursue 'modern' identities. Therefore, according to Wallis, the mobile phone as part of an assemblage, includes: (a) idea(s), which is perceived as freedom or progress; (b) practices, such as calling or texting; and (c) the effects that mobile phone usage has on users.

Mapping a mobile phone as part of an assemblage does not mean looking at the mobile phone itself but at the flow of relationships within which it is given meaning as well as its power to 'assemble specific bodies, passions and representation in particular ways' (Wallis, 2013), just as a social gathering, a coming together of individuals converging at a particular place yet comprising different ideas, practices in how to use mobile telephony, and co-presence dynamics.

\section{Methodology}

This paper is grounded in ethnographic data collected over a period of 6 weeks during the month of December, 2011. During this time, the researcher conducted 25 one-on-one semi-structured ethnographic interviews and 5 focus group discussions in the Sibou village of ElgeyoMarakwet County in western Kenya. The interviews were conducted in Kiswahili which is the national language in Kenya, but where the research participants could not understand, the research assistants who were the native of Marakwet translated. The research comes from one of the sub-tribe making up the Kalenjin tribe and so with her dialects, she was able to take care of any obvious distortion in the translation. The research assistants also were bound by a document they had signed stipulating what their translation work entailed for which they offered their consent in writing. Data was collected using digital audio recorder, having obtained permission from the research participants as well as 
field notes. Data was then processed in line with the research objectives, cleaned, clustered and analysed thematically. The interviews were designed to elicit open-ended responses to three broad and sometimes overlapping areas, namely:

a) Descriptions of personal mobile phone use patterns and preference by individual household members of Sibou in a bid to understand how time and space was being understood in the advent of mobile telephony .

b) Perceptions on the societal use and implications of mobile phone use in a community meeting dubbed "Baraza' a Swahili term for developmental meeting by local community leadership with community representatives.

c) Opinions on how mobile phones can benefit the community better.

\section{Findings}

\section{Time and space conceptualisation}

Goggin Gerard (2006, 2011, 2012), a mobile telephony theorist, acknowledges the implication of information communication technologies (ICT) for daily travel activities, but points out that scant attention has been paid to relationships between ICT and space-time constraints.

The impact of mobile telephony for everyday activities has created a sense of relaxed temporal constraints (Schwanen and Mei-Po, 2008), while in some instances it is deemed to have increased spatial and temporal flexibility. This is shown in the following testimony:

'Yes, the mobile phone has really helped me in talking to my children in Kamendi, talking to my uncles and all my relations wherever they are. It has really helped because instead of spending a lot of money, now it costs less. Take, for instance, going to Nairobi... The bus fare is Kshs. 1,000 besides lodging and food. This comes to roughly Kshs. 4,000, but now with the phone, it is very cheap, and is actually less than ksh100' (Keldo, 48 years old).

Similarly, presence is not limited to co-presence, as evidenced by increased face-to-face to mobile phone interactions (Urry, 2007). Copresence is both a location and a relation (Callon and Law, 2004), thus reemphasising the notion that presence cannot be reduced to co-presence. In this regard, co-presence questions the taken for granted assumption of time and space mediated by technologies, such as mobile phones. Even meetings that are arranged via mobile phones have been questioned, with scholars arguing that such meetings are rarely a sequence of purely face to face interactions within physical places (Katz and Aakhus, 2004; Licoppe 2004; Ling 2004). 


\section{Private and Public spaces}

Mobility also introduces new capacities to affect and be affected, what DeLanda calls 'space of possibilities'. Mobile phones also have potential tendencies to affect or transform assemblages they are connected to. For example, through mobile phones, people can link up to form a gathering, and yet as they interact within that spatial distance, the mobile phone is equally present, almost standing as the next person in the group waiting to affect or be affected. When a call comes and people are engaged in a co-present situation, the decision to take the call or not affects the identity and nature of that group and the individual engaging in a phone call conversation, by either stepping aside or answering the call in a low tone or not receiving the call at all. Mobile telephony also gives rise to new ways of organising and conducting everyday practices like farming, doing small business, and talking to friends and relatives that are far and near, hence enhancing family kinships and relationships. These new ways were not foreseen or predicted before giving rise to diachronic emergence. The ability of mobile telephony to infiltrate everyday life has influenced the conceptualisation of time and space so much that it is no longer possible to consider space in terms of dichotomised categories of here and there, near and far, private and public, or even presence and absence.

How we use our mobile phones is affected by the attention we pay to co-presence. The term 'perpetual contact', coined by Katz and Aakhus (2002), suggests a near constant co-presence facilitated by mobile telephony by directing behaviour to some extent, consequently positioning users at multiple locations at once. Swetait explains how this 'perpetual contact' has made it possible to be reached by bosses(a situation that could be termed as a private time, away from the office hours) however, he does not mind the intrusion for as long as time is saved.

'I think this mobile phone has really affected my family time, sometimes I am home with family and my boss calls on matters official, sometimes asking me to go back to work since I am one of the managers to attend to a client; but, on the other hand, I can call my juniors whom I have given my locker key and ask them to remove whatever the senior wants. That way, I do not have to travel all the way; so, it is good and bad'( Swetait, 54 years, ethnographic interview, 2012).

This narration by Swetait introduces the complexities of copresence and the acceptance of the user to the intrusion. Ideally one would imagine, office matters should be dealt with within office hours, however, due to the distance of the employee from the office, he (Swetait) does not mind being nudged to attend to official matters on an official time and place. Co-presence is more than meeting of one to one, 
here, this paper extents co-presence to one to one to intermediate communication. One is face to face to one another but also with their mobile places to connect to others or is without or outside the confines of geographical space defined by the caller. The superior officer(s) would begin by asking 'where are you?' as if to position the communication he is just about to commence. Once he establishes the location he goes beyond it and breaks the integrity of that private space to make it public.

\section{The community meetings 'Barazas'}

Ordinary these meetings would be arranged via a mobile phone call or text or word of mouth or all of these. Once the meeting is fully constituted, it would usually be under a tree or by the furrow cite. Barazas are usually seriously held meetings where clan leaders discuss matters of community interest such as development, pest infestations, accepted and reviled behaviours, it is also a meeting where political leaders occasionally attend if they wish to push any agenda. It is a meeting place for the government and the local leadership to exchange ideas concerning matters that concern the community. The use of mobile telephony was seen to have both facilitated the mobilisation of such meetings but also discouraged co-presence in terms of face to face interaction in some instance. As seen in the sentiments below as given by immediate former area legislator of Marakwet East constituency, showing how time and space has been relaxed on one hand yet constraint on the other as she narrates below:

'I pity those who came before me [meaning former area members of parliament]; I wonder how they used to do their work. For me I have personal assistants (PAs) in every village and when I need to have a meeting with them, I ask the PA to be there and then they broadcast my talk via a loud speaker and we get to talk at length with the villagers usually gathered in a baraza [meeting of opinion leaders usually clan leaders or elders and members of the community]. So you see I do not have to travel all the way this way. Mobile phone has cut unnecessary distance and at the same time brought meetings close virtually if you like.'(Ethnographic interviews data, 2011)

\section{Co-presence and mobile phone sharing}

The unpredictable nature of conversation(s) presents it as complex. The content of conversation(s) is vast, including other aspects that are not necessarily linguistic in nature such as mannerisms, gestures and symbols. Goffman (1959) uses a 'theatrical metaphor' to illuminate the issue of identity and how it is conceptualised using every day social interaction or conversation. Goffman observes that just like a 'dramaturgy', there are actions that are considered 'front stage', which are usually carried out before an audience, while those who are 'back stage' remain invisible to the audience. He argues that there is a 
distinction between the roles we play on the 'front stage' and the way we behave on the 'back stage'. In other words, social interaction or copresence comes about in and through social interactions with one another, where participants 'perform', by assuming a role and trying to create an 'impression' as much as is possible.

DeLanda's theory of assemblage and Goffman's theory of copresence agree on this novel understanding of the social, in that they see the social as being no longer reducible to a category or grouping of wholes or totalities, but rather that it is individuals within wholes who are irreducible. The very fact that we are in the presence of others influences what we do and how we think in many ways. It is an everyday, and almost taken for granted, experience that reveals a great deal about social interaction among people. According to Goffman, what is done before an audience is usually a rehearsed performance meaning that what is displayed on the front stage is the result of what is done on the back stage. For example, when two people are interacting, there are certain forms of behaviour that are deemed appropriate, certain words that are considered respectful and others that are considered disrespectful. If, for any reason, inappropriate communications are conducted in the presence of another, an immediate feeling of embarrassment follows, which can destabilise a harmonious conversation, resulting in a different form of behaviour or choice of phrases, such as "I am sorry" and/or "Forgive me", to return the otherwise awkward situation to normalcy.

Goffman also explains that for there to be a smooth front stage performance, what is done in the 'back stage' area need not come to the front stage and that when what is supposed to be hidden comes to the sight of the audience it causes embarrassment, which can also be seen as a social control mechanism. For instance, playing jokes on someone or humiliating someone before others could be a sanction of some sort for not following group norms. This attribute is evident in mobile phone sharing and varies from one cultural group to another.

Although the mobile phone has become an increasingly personalised device, there are some contexts in which sharing its functions with others challenges the assumption of the individual nature of how it is used. Mobile phone functions enable the users to share the device at will with relatives and even strangers. In contexts where sharing is the norm, the sharing of mobile telephony is incorporated with other support systems, such as communal meetings and group meetings, which are most often scheduled for and carried out under specific trees or certain agreed-upon venues. Mobile phones, consequently, bring people together in new ways, but also combine with older support systems complementarily. Burell (2010) defines mobile phone sharing as an informal, non-enumerative resource for distributing activities where multiple individuals have a relationship with a single device as a purchaser, owner, possessor, operator and/or user. This implies that as 
the original holder, one grants to another the partial use, enjoyment or possession of a thing, resource or place (p. 230). In this study, mobile phone sharing is the ownership of, and/or access to, a mobile phone by the owner or designated custodian, who makes the device available for use by someone other than themselves for free, or with a token given in return.

Mobile phone sharing gathers people together, therefore encouraging co-presence. According to the research participants, mobile phone sharing greatly encouraged interpersonal communication. For instance, in the teenage cohort, the kind of interactions that emerged when they converged to listen to the radio or news, were not limited. After listening to news they would then embark on their everyday social interactions, which lasted even longer. The quote below explains this better:

'We usually call each other either via texting or by word of mouth. Then we meet over here ([pointing to the hillside]. We listen to news, entertainment and our favourite soccer teams and how they have fared. Afterwards we just talk about stuff from school work, politics, anything' (Interviewee 7).

The notion of sharing assumes a free exchange among people sharing the mobile phone device. However; sharing also introduces limitations to social interactions, consequently affecting issues of gender roles, power differentiation and shifts in time and space conceptualisation. For instance, only those who contribute to cost sharing have access to mobile phone sharing. As a result, only they can gather together for whatever reasons. A person who is seen as not contributing is often locked out, and is therefore not invited to join the rest at the place of gathering. This was particularly the case with teenage groups: 'For those who don't contribute either by buying air time, or charging the phone, we just block them off, we don't want parasites, we must cost share' (Kipkiyeny ,19 years). Mobile phone sharing has also been approached as one of the ways that poverty can be reduced or 'shared', instead of each person purchasing a phone. It is assumed that since one does not necessarily need to own a mobile phone, the cost of purchasing such a device could be skipped, saving the said money for matters of development. This is, however, contrary to observations made by one participant, as the ethnographic data below shows:

You see I did not go to school. So when I receive a text I ask my husband to read it. Sometimes he is not around, like when he goes to watch over our cattle, and then I ask anybody who is around. I just hear the sound and I ask someone to read what it is saying (Chepsiro , 58 years old).

The narrative of Chepsiro is a typical example of the utility of mobile telephony by the majority of residents living in the Marakwet 
district. Even though theoretically the mobile phone belonged to Chepsiro, her lack of literacy meant that she had to trust her husband to decipher all the texts on her phone, thus demonstrating the need that often exists for phone sharing (see Chapter Three). Mobile phone sharing in itself, according to Chepsiro's case, does not necessitate poverty reduction or development, because sharing is dependent on other factors, such as what is shared, how it is shared, the frequency of the sharing, with whom and for what purpose. In the absence of her husband, she would allow someone else to help read messages, opening the door to unprecedented trust issues. Essentially, this model of mobile phone use necessarily involves co-presence.

This attribute is evident in mobile phone sharing and varies from one cultural group to another. For instance, among the elderly, mobile phone sharing is understood as a common and normal thing to do, and anyone who refuses to share their phone is reprimanded. Similarly, the young (especially teens) will only share if there is an understanding that sharing is done in turns, and when they see situations in which an individual is barred from mobile sharing as a reciprocity failure. The following quote from an ethnographic interview demonstrates this:

'I do not have to worry because I don't own a mobile phone. All I need to do is give the owner twenty bob (twenty Kenya shillings) to charge his phone or bamba twenty (twenty Kenya shillings) for a top up. Then I can come along and we listen to the news together with other friends. So it is not a must to own a phone. We just do cost sharing or else you will be punished by your peers if you don't contribute' (Kipkebut, 22).

The embarrassment revealed in the above narrative exists among peers but can also be a marker of social status. For example, it is usually the case that a boss embarrasses a junior worker and not the other way round. In other words, the management between front stage and back stage is crucial to the management of self-image or identity. In the previous narrative, Chepsiro shares with her husband as a priority and only considers asking others if her husband is away herding cattle, making gender roles even in mobile phone sharing quite marked. The second narrative by Kipkebut shows a kind of mutual of interaction related to the fear of being punished by peers. He shares by contributing, because he does not want to feel embarrassed or lose face. This interaction can also be experienced in mobile telephony as peopleinteracting. On one hand, they can be face to face with others, and on the other, face to face with their mobile phones, which affects social relations.

When mobile phone users focus more on their phones, for instance, while exchanging texts with significant others, an immediate co-present other is somewhat temporarily shut out. The ability to shift one's attention at will affects not only one's self-image before another, 
but also contributes to how identity is created, nurtured and shifted in human-technology interactions. Identity, therefore, is presented as fluid. For instance, a person who does not want to be contacted can control who calls by sending a text to say that they are busy or even put their phone on vibration mode so they can claim it was inaudible. One can also claim to be in a meeting to avoid being contacted by certain individuals that they have chosen not to converse with.

This act of blocking others by 'meetings' or putting one's mobile phone in the silent mode is one means of exercising control over others. When two or more individuals meet up to converse under a tree or at a market place, as was the case in Marakwet, they are members of Marakwet community (i.e. at the intermediate level) who are using mobile telephony, a global technology (macro level), within Kenya as a country. In actual fact, the use of mobile telephones facilitates a copresence that links all levels of society from micro, intermediate and macro levels.

Therefore, an understanding of co-presence is critical in linking the interactions at a micro (co-presence) and macro level of society. Understanding mobile phone use as a mode of development will involve the individual user and those they link with via mobile phone, government apparatuses, non-governmental organisations, mobile phone operators and other institutions, such as banks. It also involves the specific contexts in which a mobile phone is used and specific ways that the technology is manipulated by users, in line with either already established needs or emerging needs.

Assemblage theory thus provides a more complex way of looking at mobile phone use as discussed above, which involves social networks, business linkages, cultural input, skill of use and the capacities of the mobile telephone as a communication gadget, among other things. Therefore, when one picks up a phone to receive a call or a text, one is immediately linked to the caller, the context of the caller and the place or sometimes places (be they physical or electronic spaces/places mediated by the mobile phone) they are in. So, the content of discussions or exchange(s) could touch on social encounters, business initiatives, market prices or bills. The list is inconclusive. An interaction such as this shows that presence is not limited to co-presence but includes multiple places or presences. This study thus extends Goffman's co-presence to include multiple presences in the wake of mobile technologies such as the mobile phone

\section{Conclusion}

Mobile telephone uses revealed a connection between mobile telephones, users and their context, all coming together to form assemblages that have various heterogeneous components, such as people, place, horn and social interactions. Mobile telephony as a social assemblage has had influence on social interactions in Marakwet, some 
that enhances community life while some influences have defiled the private life for instance when a boss calls off duty hours to instruct juniors on what to do.

Use of mobile telephones in Baraza's was not entirely frowned upon as the then area legislator was a welcome presence to the meeting howbeit virtually.

There is need to study how mobile telephony has penetrated the otherwise private times of the workers who travel to be with families over the weekend and how power and gender plays out. For instance does the gender of the boss matter when giving instructions? Can the employee avoid a phone call by bosses when not on duty? Are there consequences? Who regulates communication outside office hours and among other issues?.

Time and space or place has been affected on both fronts, where they have been relaxed on one hand yet constraint on another making the distinction blurred, there is therefore no case for here or there debates, public or private spaces since by a touch of a button any virtual place is made a reality. This study has attempted to extent Goffmanian copresence beyond the physical locale of face-to-face but also to include mediated presence via the mobile telephony.

\section{References}

Baym, N (2010).

Personal connections in the Digital Age: Digital Media and Society: Cambridge, Polity.

Campbell , S.W., \& Kwak, N. (2011)

Mobile communication and civil society: Linking patterns and places of use to engagement with others in public. Human Communication Research, 37: 207-222

DeLanda, M. (2006).

A New Philosophy of Society: Assemblage Theory and Social Complexity. London. Continuum.

Goffman, E. (1963).

Behaviour in Public Places. New York: Free Press.

Goffman,E. (1959) .

The Presentation of Self in Everyday Life. Garden city. NY.

Doubleday

Goggin, G. (2006).

Cell Phone Culture: Mobile Technology in Everyday Life. London: Routledge.

Goggin, G. (2011).

Global MOBILE Media. New York: Routledge

Goggin, G., (2012).

Encoding place: The politics of mobile location technologies. In: Wilken, R. and Goggin, G., (ed.) Mobile Technology and Place, pp: 198-212. 
Ito, M. and D. Okabe. (2003).

"Mobile Phones, Japanese Youth, and the RePlacement of Social Contact. In Ling, R. (ed.). Front Stage - Back Stage: Mobile Communication and the Renegotiation of the Public Sphere. Grimstad, Norway

Langmia, K. (2016).

Social Media 'Teleco-presence' Theory of Identity. Journal of Social media in Society, 5: 265-290

Katz, J.E. and Aaakhus, M.A. (eds.) (2002).

Perpetual Contact: Mobile Communications, Private Talk, Public Performance. Cambridge: Cambridge University Press.

Licoppe, C. (2004).

Connected presence: the emergence of a new repertoire for managing Social relationships in a changing communications technoscape. Journal of Environment and Planning: Society and Space, 22: $135-56$.

Ling, R. and Birgitte, Y. (2002).

"Hyper-coordination via mobile phones in Norway." pp. 139-169 in Perpetual Contact: Mobile Communication, Private Talk, Public Performance, edited by J. E. Katz and M. Aakhus. Cambridge: Cambridge University Press.

Murtagh, G.M. (2002). "Seeing the "Rules": Preliminary Observations of Action, Interaction and Mobile Phone Use." pp. 81-91 in Wireless World: Social and Interactional Aspects of the Mobile Age, edited by B. Brown, N. Green, and R. Harper. New York: Springer.

Plant, Sadie. (2001).

"On the Mobile: The Effects of Mobile Telephones on Social and Individual Life." Motorola ,University of California

Przybylski, A, K., \& Weinstein, N. (2012).

Can you connect with me now? How the presence of mobile communication technology influences face-to-face conversation quality. Journal of Social and Personal Relationships, 1-10

Schwanen . T. and Mei-Po. K., (2008).

The Internet, Mobile Phone and Space- Time Constraints. Geoforum, 39(3): 1362-1377.

Urry, J. (2007).

Mobilities. Cambridge: Polity.

Wallis, C. (2013).

Technomobility in China: Young Migrant Women and Mobile Phones. NY: New York University Press.

Weilenmann, A and Larsson, C. (2002).

Local use and Sharing of Mobile phones. In B. Brown, N. Green and R. Harper (eds.) Wireless World: social and interaction aspects of the mobile Age(92-107).London: Sage. 